\title{
IMPASSES NA CONFORMAÇÃO DA REDE DE ATENÇÃO PSICOSSOCIAL PELA PERSPECTIVA DOS AGENTES INSTITUCIONAIS
}

\author{
IMPASES EN LA CONFORMACIÓN DE LA RED DE \\ ATENCIÓN PSICOSOCIAL POR LA PERSPECTIVA \\ DE LOS AGENTES INSTITUCIONALES \\ IMPASSES IN THE FORMATION OF THE \\ PSTCHOSOCIAL CARE NETWORK FROM THE \\ PERSPECTIVE OF INSTITUTIONAL AGENTS
}

\author{
Annabelle de Fátima Modesto Vargas ${ }^{1}$ e Mauro Macedo Campos ${ }^{1}$
}

${ }^{1}$ Universidade Estadual do Norte Fluminense Darcy Ribeiro, Campos dos Goytacazes/RJ, Brasil

\begin{abstract}
RESUMO: O artigo analisa a estruturação da Rede de Atenção Psicossocial (RAPS) em um município do Estado do Rio de Janeiro, no que se refere ao atendimento às necessidades decorrentes do uso de álcool, crack e outras drogas, a partir da visão de profissionais de uma unidade do CAPSad III. A construção dos dados foi realizada por meio de observação participante, anotações em diário de campo e entrevistas com profissionais da equipe de saúde mental. Através das observações do cotidiano do equipamento de saúde, percebeu-se uma falta de diálogo entre as categorias profissionais, bem como o desconhecimento das políticas de saúde mental e do modus operandi dos CAPS. Tais impasses associam-se ao preconceito e ao estigma ligados à loucura e a quase ausência de capacitação e embasamento técnico para atuação, que foram apontados pelos profissionais como os principais motivos que dificultam a articulação entre os componentes da RAPS.
\end{abstract}

PALAVRAS-CHAVE: Rede de Atenção Psicossocial; Saúde Mental; Álcool; Drogas.

RESUMEN: El artículo analiza la estructuración de la red de atención psicosocial (RAPS) en un municipio del estado de Río de Janeiro, en relación con la atención a las necesidades derivadas del uso de alcohol, crack y otras drogas, desde el punto de vista de una unidad de CAPSad III. La construcción de los datos se realizó por medio de la observación participante, notas en el diario de campo y entrevistas con los profesionales del equipo de salud mental. A través de las observaciones de la vida cotidiana de los equipamientos de salud, se percibió falta de diálogo entre las categorías profesionales, así como el desconocimiento de las políticas de salud mental y el modus operandi de los CAPS. Tales impases están asociados con el prejuicio y al estigma en relación con la locura y la casi ausencia de capacitación y base técnica para actuación, que fueron señaladas por los profesionales como las principales razones que llevan a la dificultad de articulación entre los componentes de la RAPS.

PALABRAS CLAVE: Red de Atención Psicosocial; Salud mental; Alcohol; Drogas.

ABSTRACT: This article analyzes the structuring of the Psychosocial Care Network (RAPS) in a city in the State of Rio de Janeiro, in relation to the attendance to the needs arising from the use of alcohol, crack and other drugs, from an unit of CAPSad III's point of view. The construction of the data was done through participant observation, field diary notes and interviews with professionals of the mental health team. Through the observations of the daily life of the health equipment, a lack of dialogue between the professional categories was noticed, as well as the lack of knowledge about the mental health policies and the modus operandi of the CAPS. Such impasses are associated with prejudice and the stigma attached to madness and the almost complete absence of training and technical basis for action, which were pointed out by professionals as the main reasons that lead to difficulties of articulation between the components of the RAPS.

KEYWORDS: Network of psychosocial care services; Mental health; Alcohol; Drugs. 


\section{Introdução}

O modelo de Redes de Atenção à Saúde (RASs) foi constituído de modo que se tornasse possível fornecer à população uma atenção integral e contínua, com sua coordenação partindo da atenção primária à saúde (Mendes, 2009). De acordo com o autor, as RASs "são organizações poliárquicas de conjuntos de serviços de saúde" (Mendes, 2010, p. 2.300), vinculados entre si, por objetivos compartilhados, missão única e ações interdependentes e cooperativas.

Com a constituição de uma rede coordenada pela atenção primária, os serviços poderiam ser ofertados no tempo, lugar e com a qualidade correta, de forma humanizada e com responsabilidades sanitárias e econômicas compartilhadas. Assim, a partir da complexa estrutura organizacional do sistema público de saúde, propostas com essas características poliárquicas têm surgido, de forma que toda a rede funcione articuladamente, sendo capaz de fornecer um cuidado integral à população como um todo. Uma ramificação dessas redes que se estabelece no âmbito do SUS, a partir da Portaria $n^{\circ} 3.088$ de 2011, é a Rede de Atenção Psicossocial (RAPS) (Ministério da Saúde, 2011).

Logo de início a legislação já descreve que a RAPS é instituída para "pessoas com sofrimento ou transtorno mental e com necessidades decorrentes do uso de crack, álcool e outras drogas". Durante boa parte do século XX os "termos" adotados pela sociedade em geral, e pelos profissionais da área, em particular, caracterizavam uma pessoa por seu estatuto médico, jurídico ou social, como os "alienados", os "doentes mentais", os "toxicômanos", os "psicopatas”. A partir da década de 1990, ganham força as preocupações com termos considerados estigmatizantes, tendo por base a conhecida formulação teórica de Erving Goffman. Com efeito, passam a ser utilizados, dessa maneira, tanto no cotidiano dos trabalhadores quanto nas políticas a terminologia "pessoas com transtornos mentais", "pessoas em sofrimento psíquico", "pessoas que fazem uso de álcool e outras drogas".

A referida Portaria de 2011 apresenta uma extensa lista de objetivos específicos da RAPS e que dizem respeito, especialmente, à importância da articulação entre as diversas esferas de atenção à saúde. São eles:

(I) promover cuidados em saúde especialmente para grupos mais vulneráveis (criança, adolescente, jovens, pessoas em situação de rua e populações indígenas);

(II) prevenir o consumo e a dependência de crack, álcool e outras drogas;

(III) reduzir danos provocados pelo consumo de crack, álcool e outras drogas;

(IV) promover a reabilitação e a reinserção das pessoas com transtorno mental e com necessidades decorrentes do uso de crack, álcool e outras drogas na sociedade, por meio do acesso ao trabalho, renda e moradia solidária;

(V) promover mecanismos de formação permanente aos profissionais de saúde;

(VI) desenvolver ações intersetoriais de prevenção e redução de danos em parceria com organizações governamentais e da sociedade civil;

(VII) produzir e ofertar informações sobre direitos das pessoas, medidas de prevenção e cuidado e os serviços disponíveis na rede;

(VIII) regular e organizar as demandas e os fluxos assistenciais da Rede de Atenção Psicossocial;

(IX) monitorar e avaliar a qualidade dos serviços por meio de indicadores de efetividade e resolutividade da atenção. (Ministério da Saúde, 2011 , grifo nosso) 
De acordo com Zeferino e colaboradores (2016), a saúde mental, por muito tempo, foi um campo de exclusão. No entanto, discussões mais recentes sobre o modelo biomédico, que abordam a cronificação dos usuários, a violação de direitos humanos e de cidadania, possibilitaram o surgimento de propostas sociais, políticas e científicas inovadoras, de valorização dos sujeitos e estabelecimento de uma nova forma de cuidar em saúde. Uma dessas propostas é a Rede de Atenção Psicossocial (RAPS). Face ao exposto, busca-se neste artigo analisar a estruturação da RAPS, no que se refere ao equipamento público de atendimento às necessidades decorrentes do uso de álcool, crack e outras drogas, a partir da visão de profissionais que atuam em um CAPSad III.

\section{Método}

O artigo em questão é parte de uma pesquisa de doutoramento, financiada pela Coordenação de Aperfeiçoamento de Pessoal de Nível Superior (CAPES). Foi realizada em um Centro de Atenção Psicossocial Álcool e Drogas (CAPSad III), localizado em um município do Estado do Rio de Janeiro. Vale ressaltar que não existiram conflitos de interesse.

A pesquisa desenvolvida é de cunho qualitativo e contou com a técnica da observação participante e anotações em diário de campo (Minayo, 1998). A conjugação destes métodos permitiu maior acuidade no trato das informações e dados de campo. Por um lado, a observação participante possibilita o conhecimento aprofundado de certas áreas ou dimensões da sociedade (Velho, 1999) dificilmente auferidas apenas com as entrevistas. Como argumenta Bonet (2004), este método, legado de Malinowski, seria uma mistura de isolamento e observação, participação e intrometimento. Já o diário resguardou apontamentos essenciais para a análise compilada do que fora coletado no campo de pesquisa.

Além da imersão no campo, foram entrevistados profissionais de todas as categorias constantes na unidade. As entrevistas foram gravadas, transcritas e analisadas pela técnica da análise de conteúdo (Bardin, 2010). A tabela 1 apresenta o quantitativo dos profissionais que atuam na unidade e o número de entrevistados:

Tabela 1: Quantitativo profissional

\begin{tabular}{|c|c|c|c|c|}
\hline Categoria Profissional & $\begin{array}{c}\text { Quantidade } \\
\text { CAPSad III }\end{array}$ & $\mathbf{( \% )}$ & $\begin{array}{c}\text { Número de } \\
\text { Entrevistados }\end{array}$ & $\mathbf{( \% )}$ \\
\hline Enfermeiro & 8 & 22,2 & 6 & 75 \\
\hline Técnico de enfermagem & 12 & 33,3 & 5 & 41,6 \\
\hline Assistente social & 4 & 11,1 & 3 & 75 \\
\hline Psicólogo & 2 & 5,6 & 2 & 100 \\
\hline Médico psiquiatra & 2 & 5,6 & 1 & 50 \\
\hline Recepcionista & 1 & 2,8 & 1 & 100 \\
\hline Assistente administrativo & 1 & 2,8 & 1 & 100 \\
\hline Servente & 2 & 5,6 & 1 & 50 \\
\hline Vigia & 3 & 8,2 & 1 & 33,3 \\
\hline Técnico de Farmácia & 1 & 2,8 & 1 & 100 \\
\hline Total & 36 & 100 & 22 & 61,1 \\
\hline
\end{tabular}

Fonte: elaborado pelos autores 
Além da observação participante, anotação em diário de campo e entrevistas, foram utilizados dados coletados no portal virtual do município e do Cadastro Nacional de Estabelecimentos de Saúde (CNES/DATASUS). Recorremos, também, a materiais e documentos impressos e online disponibilizados durante o trabalho de campo, que também fizeram parte da construção dos materiais necessários à argumentação proposta em relação ao restante da rede, visto que o lócus da pesquisa foi o CAPSad III. Foram utilizados nomes fictícios para representar os profissionais entrevistados. Essa pesquisa foi aprovada em Comitê de Ética em Pesquisa.

\section{Discussão e Resultados}

A preocupação com o funcionamento em rede parece não se dar apenas em função dos aspectos teóricos e por pesquisas que demonstraram dessa dinâmica de trabalho. Surge também de toda uma argumentação que parte, especialmente, dos profissionais em saúde mental - o que pôde ser constatado por este artigo - de que o processo de desinstitucionalização, ou fechamento total dos manicômios, ganha força com o pleno funcionamento dessa rede. Deste modo, os serviços seriam capazes de fornecer apoio integral aos usuários do SUS e seus familiares, diante da articulação das equipes de saúde, principalmente no apoio e assistência à chamada pelos profissionais da área, de "crise psiquiátrica" . A tabela 2 demonstra, a partir da Portaria ${ }^{\circ} 3.088$ de 2011 , quais os serviços que compõem a RAPS.

1 Dell'Acqua e Mezzina (1991) destacam a complexidade de significados envolvidos na chamada "crise" psiquiátrica e estabelecem que ao menos três parâmetros podem ser identificados nessas situações: sintomatologia psiquiátrica grave e aguda; ruptura de relações sociais e familiares; recusa de qualquer forma de contato e intervenções. 
Tabela 2: Componentes da Rede de Atenção Psicossocial (RAPS)

\begin{tabular}{|c|c|}
\hline Componente & Pontos de Atenção \\
\hline \multirow{5}{*}{$\begin{array}{l}\text { Atenção Básica } \\
\text { em Saúde }\end{array}$} & Unidade Básica de Saúde \\
\hline & Núcleo de Apoio a Saúde da Família \\
\hline & Consultório na Rua \\
\hline & $\begin{array}{l}\text { Apoio aos Serviços do componente Atenção } \\
\text { Residencial de Caráter Transitório }\end{array}$ \\
\hline & Centros de Convivência e Cultura \\
\hline $\begin{array}{l}\text { Atenção Psicossocial } \\
\text { Estratégica }\end{array}$ & $\begin{array}{l}\text { Centros de Atenção Psicossocial, } \\
\text { nas suas diferentes modalidades }\end{array}$ \\
\hline \multirow{3}{*}{$\begin{array}{l}\text { Atenção de Urgência } \\
\text { e Emergência }\end{array}$} & SAMU 192 \\
\hline & Sala de Estabilização \\
\hline & $\begin{array}{l}\text { UPA } 24 \text { horas e portas hospitalares de atenção à } \\
\text { urgência/pronto socorro, Unidades Básicas de Saúde }\end{array}$ \\
\hline \multirow{2}{*}{$\begin{array}{l}\text { Atenção Residencial } \\
\text { de Caráter Transitório }\end{array}$} & Unidade de Acolhimento \\
\hline & Serviço de Atenção em Regime Residencial \\
\hline \multirow[b]{2}{*}{ Atenção Hospitalar } & Enfermaria especializada em Hospital Geral \\
\hline & $\begin{array}{c}\text { Serviço Hospitalar de Referência para Atenção às Pessoas } \\
\text { com sofrimento ou transtorno mental e com necessidades } \\
\text { decorrentes do uso do crack, álcool e outras drogas }\end{array}$ \\
\hline \multirow{2}{*}{$\begin{array}{c}\text { Estratégias de } \\
\text { Desinstitucionalização }\end{array}$} & Serviços Residenciais Terapêuticos \\
\hline & Programa de Volta para Casa \\
\hline \multirow{2}{*}{$\begin{array}{c}\text { Estratégias de } \\
\text { Reabilitação Psicossocial }\end{array}$} & Iniciativas de Geração de Trabalho e Renda \\
\hline & Empreendimentos Solidários e Cooperativas Sociais \\
\hline
\end{tabular}

Fonte: Portal do Ministério da Saúde. Disponível em: http://portalsaude.saude.gov.br/index.php/o-ministerio/principal/secretarias/803-sas-raiz/daet-raiz/saude-mental/12-saude-mental/12588-raps-rede-deatencao-psicossocial

Todos esses dispositivos deveriam estar organizados dentro da lógica de uma rede integral, em que se pudesse estabelecer o acolhimento, vínculo, responsabilização, além de garantir mais autonomia aos usuários (Franco \& Merhy, 2004). Segundo Souza, Abrahão e Guljor (2016), no caso das ações para enfrentamento do uso abusivo de drogas, o funcionamento da rede de forma integral é premissa fundamental, uma vez que um conjunto de instituições precisa trabalhar em uma perspectiva intersetorial e interdisciplinar, compartilhando o cuidado a essa população. Para as autoras, o pressuposto é de que o trabalho em rede funcione de modo a potencializar essas ações de cuidado, propiciando a construção de solidariedade, ao invés de competição. A integração entre os atores e serviços também é fundamental, levando-se em conta a multiplicidade de relações sociais e uma produção quase "artesanal" (Souza, Abrahão, \& Guljor, 2016, p. 207) de formas de lidar com usuários de drogas no cotidiano das cidades, trabalhando com pessoas e as conectando em redes, e com isso, abrindo novos caminhos para o fortalecimento das ações.

A partir das discussões empreendidas e da percepção da importância atribuída à RAPS pela bibliografia especializada para a operacionalização do trabalho em saúde mental, especialmente na questão do uso de álcool e outras drogas, buscamos entender, neste artigo, 
a partir das falas dos profissionais e da observação de campo, como essa rede encontra-se estruturada localmente. Mesmo que a pesquisa não tenha como foco uma abordagem que abarque toda RAPS do município estudado, e sim a apenas um de seus dispositivos, será feita uma breve apresentação desses locais e análise das potencialidades e dificuldades observadas pelos profissionais atuantes no CAPSad III, a respeito do trabalho em rede.

Como especificado, a RAPS não é composta apenas por equipamentos específicos que fazem parte da direção de saúde mental no âmbito municipal. Ao contrário, como o pressuposto do trabalho em rede é atingir a integralidade das ações, possibilitando o acesso a todos os serviços de forma conjunta, são também considerados componentes dessa rede serviços vinculados à Atenção Básica, como a Estratégia Saúde da Família, os serviços de urgência e emergência e a atenção hospitalar. Por seu recorte e escopo metodológico, a pesquisa de campo não englobou todos os componentes da RAPS, apenas o CAPSad III, como já ressaltado. Para conhecimento do restante da RAPS, nos orientamos pelas falas dos profissionais, documentos disponibilizados pelos próprios operadores do serviço de saúde, lócus da pesquisa, e gestores da saúde mental, além de informações contidas no portal eletrônico do município. A tabela 3 apresenta os serviços de saúde existentes no município e que, de acordo com a sua funcionalidade, poderiam² integrar a RAPS do município.

2 Utilizamos a palavra "poderiam" no tempo verbal futuro do pretérito por entender que embora, como analisado posteriormente, todos esses serviços possam integrar a Rede de Atenção Psicossocial, como previsto na política do Ministério da Saúde, a articulação entre as equipes não ocorre de fato, havendo também um desconhecimento sobre quais serviços comporiam a RAPS. 
Tabela 3: Componentes da RAPS do município incluindo a Atenção Básica, Hospitalar e Urgência/Emergência

\begin{tabular}{|c|c|c|c|}
\hline Componente & Ponto de Atenção & $\begin{array}{l}\text { Total de } \\
\text { Unidades }\end{array}$ & Descrição do Serviço \\
\hline \multirow{4}{*}{$\begin{array}{l}\text { Atenção } \\
\text { Básica }\end{array}$} & $\begin{array}{l}\text { Unidade Básica } \\
\text { de Saúde (UBS) }\end{array}$ & 45 & $\begin{array}{c}\text { Unidade Básica de Saúde Tradicional. } \\
\text { As UBS contam em suas equipes com } \\
\text { médicos (clínicos, pediatras e gine- } \\
\text { cologista-obstetras), enfermeiros, } \\
\text { dentistas, auxiliares de enfermagem e } \\
\text { pessoal de apoio técnico. A demanda } \\
\text { atendida se apresenta como espontânea } \\
\text { e/ou encaminhada por outros serviços } \\
\text { (Elias et al., 2006). }\end{array}$ \\
\hline & $\begin{array}{l}\text { Unidade Básica } \\
\text { de Saúde da Família } \\
\text { (UBSF) }\end{array}$ & 16 & $\begin{array}{l}\text { São Unidades Básicas de Saúde que } \\
\text { contam com Equipes de Saúde da } \\
\text { Família, em conformidade com as } \\
\text { normas do Ministério da Saúde a } \\
\text { partir da implantação da Estratégia } \\
\text { Saúde da Família. Elas obedecem ao } \\
\text { preceito da delimitação da área de } \\
\text { abrangência com adscrição de } \\
\text { clientela (Elias et al., 2006). }\end{array}$ \\
\hline & $\begin{array}{c}\text { Equipe de } \\
\text { Consultório na Rua }\end{array}$ & 1 & $\begin{array}{l}\text { Busca ampliar o acesso da população de } \\
\text { rua aos serviços de saúde, ofertando, de } \\
\text { maneira oportuna, atenção integral à } \\
\text { saúde para esse grupo populacional. }\end{array}$ \\
\hline & $\begin{array}{l}\text { Programa de } \\
\text { Matriciamento }\end{array}$ & 1 & \begin{tabular}{|c|} 
Busca desenvolver ações junto às \\
unidades básicas e equipes da Estratégia \\
Saúde da Família, compartilhando o \\
cuidado e encaminhando pacientes com \\
transtornos mentais. \\
\end{tabular} \\
\hline \multirow{4}{*}{$\begin{array}{l}\text { Atenção } \\
\text { Psicossocial } \\
\text { Estratégica }\end{array}$} & CAPS Infantil & 1 & $\begin{array}{l}\text { Atende crianças e adolescentes com } \\
\text { transtornos mentais. }\end{array}$ \\
\hline & CAPS II & 1 & $\begin{array}{l}\text { Atende adultos com transtornos } \\
\text { mentais severos e persistentes. }\end{array}$ \\
\hline & CAPS III & 1 & $\begin{array}{c}\begin{array}{c}\text { Atende adultos com transtornos mentais } \\
\text { severos e persistentes, com leitos para } \\
\text { internação } 24 \text { horas. }\end{array} \\
\end{array}$ \\
\hline & $\begin{array}{c}\text { CAPSad III } \\
\text { (locus da pesquisa) }\end{array}$ & 1 & $\begin{array}{l}\text { Atende adultos em uso prejudicial } \\
\text { de álcool e outras drogas, com } \\
\text { acolhimento no leito } 24 \text { horas. }\end{array}$ \\
\hline \multirow{3}{*}{$\begin{array}{l}\text { Atenção de } \\
\text { Urgência e } \\
\text { Emergência }\end{array}$} & SAMU 192 & 1 & $\begin{array}{l}\text { Serviço de Atendimento } \\
\text { Móvel de Urgência. }\end{array}$ \\
\hline & UPA & 1 & $\begin{array}{c}\text { Unidade de Pronto Atendimento } \\
\text { para atendimento de urgência } \\
\text { e emergência } 24 \text { horas. }\end{array}$ \\
\hline & $\begin{array}{l}\text { Pronto Socorro } \\
\text { Psiquiátrico } \\
\text { (PU-Psiquiátrico) }\end{array}$ & 1 & $\begin{array}{l}\text { Atendimento } 24 \text { horas para } \\
\text { emergências psiquiátricas. }\end{array}$ \\
\hline
\end{tabular}




\begin{tabular}{|c|c|c|c|}
\hline Componente & Ponto de Atenção & $\begin{array}{l}\text { Total de } \\
\text { Unidades }\end{array}$ & Descrição do Serviço \\
\hline $\begin{array}{c}\text { Atenção } \\
\text { Residencial } \\
\text { de Caráter } \\
\text { Transitório }\end{array}$ & $\begin{array}{c}\text { Unidade de } \\
\text { Acolhimento } \\
\text { Infanto-Juvenil (UAI) }\end{array}$ & 1 & $\begin{array}{l}\text { Atendimento a crianças e adolescentes } \\
\text { em recuperação ao uso de substâncias } \\
\text { psicoativas por um, até seis meses. }\end{array}$ \\
\hline \multirow{6}{*}{$\begin{array}{l}\text { Atenção } \\
\text { Hospitalar }\end{array}$} & Hospital 1 & 1 & $\begin{array}{l}\text { Hospital geral municipal de médio porte. } \\
\text { Não há leitos psiquiátricos instalados. }\end{array}$ \\
\hline & Hospital 2 & 1 & $\begin{array}{l}\text { Hospital geral de grande porte com } \\
\text { característica de urgência e emergên- } \\
\text { cia. Referência regional. Não há leitos } \\
\text { psiquiátricos instalados. }\end{array}$ \\
\hline & Hospital 3 & 1 & $\begin{array}{l}\text { Hospital de pequeno porte com } \\
\text { característica de centro de especiali- } \\
\text { dade. Atendimento ambulatorial de } \\
\text { médicos psiquiatras e psicólogos. }\end{array}$ \\
\hline & Hospital 4 & 1 & $\begin{array}{l}\text { Hospital filantrópico de grande porte } \\
\text { para procedimentos eletivos. Não há } \\
\text { leitos psiquiátricos instalados. }\end{array}$ \\
\hline & Hospital 5 & 1 & $\begin{array}{l}\text { Hospital filantrópico de grande porte, } \\
\text { para procedimentos eletivos, com } \\
\text { habilitação para tratamento de câncer. } \\
\text { Não há leitos psiquiátricos instalados. }\end{array}$ \\
\hline & Hospital 6 & 1 & $\begin{array}{c}\text { Hospital filantrópico de } \\
\text { grande porte, com habilitação } \\
\text { de maternidade de alto risco. } \\
\text { Não há leitos psiquiátricos instalados. }\end{array}$ \\
\hline \multirow{2}{*}{$\begin{array}{l}\text { Estratégias } \\
\text { de Desinsti- } \\
\text { tucionaliza- } \\
\text { ção }\end{array}$} & $\begin{array}{l}\text { Projeto Municipal de } \\
\text { Desinstitucionali- } \\
\text { zação dos Hospitais } \\
\text { Psiquiátricos }\end{array}$ & 1 & $\begin{array}{l}\text { Busca estabelecer condições para que } \\
\text { os pacientes moradores dos hospitais } \\
\text { psiquiátricos possam ser reinseridos } \\
\text { socialmente e / ou retornar às famílias. }\end{array}$ \\
\hline & $\begin{array}{l}\text { Residência } \\
\text { Terapêutica Tipo II }\end{array}$ & 1 & $\begin{array}{c}\text { Atende usuários egressos de longos } \\
\text { períodos de inter nação psiquiátrica } \\
\text { com características de moradia e uma } \\
\text { equipe de cuidadores. }\end{array}$ \\
\hline
\end{tabular}

Fonte: Desenvolvido pela autora a partir da literatura (Elias et al., 2006), de informações e material digital fornecido pelo município durante o trabalho de campo e dados disponíveis no CNES/DATASUS.

Pode-se perceber que o município poderia contar com uma RAPS estruturada, uma vez que há componentes em todos os níveis de atenção, desde a atenção básica, passando pela hospitalar, até as estratégias de desinstitucionalização. No entanto, a empiria demonstra que essa rede ainda funciona de modo precário, embora existam esforços em contrário e tentativas de articulação. O município conta com 45 UBS funcionando sem equipes de saúde da família, o que escapa das orientações do Ministério da Saúde (MS), que entende a Estratégia Saúde da Família (ESF) como uma estratégia para a reorganização da Atenção Básica (Ministério da Saúde, 2012). Para o MS, a Atenção Básica, por sua alta capilaridade e descentralização, estando próxima da vida das pessoas, constitui o contato preferencial dos usuários com o restante da rede de atenção à saúde, sendo por isso, fundamental para a estruturação de todos os serviços. 
O processo de implantação da ESF no município foi permeado por disputas políticas, o que desestruturou toda a rede, acarretando em propostas desvinculadas das políticas nacionais. O trabalho de campo demonstra tal fato com clareza, como vemos na passagem a seguir:

uma coisa que eu acho que aqui dificulta muito é a gente não ter um PSF, ESF agora né, Estratégia Saúde da Família... fortalecido. Logo que eu comecei a trabalhar aqui no CAPS, foi quando teve a extinção dos PSFs, o município perdeu a concessão do programa... pelo Ministério da Saúde. E aí acabaram os PSFs e a gente ficou só com as UBS, então isso também dificultou muito. Porque às vezes um paciente que estava aqui, mas ficou sumido, era mais fácil se a gente acionasse o PSF e pudesse fazer essa ponte. (Lúcia)

Essa profissional, apesar de não conhecer todo o processo que acarretou na extinção do Programa Saúde da Família local e os motivos de seu reestabelecimento, ressalta que a inexistência do programa, causa prejuízos para toda a rede, inclusive para o trabalho realizado nos CAPS. Ela diz que hoje, mesmo com a implantação de algumas equipes de saúde da família no município, o trabalho "existe, mas muito pouco" ressaltando que "a gente perdeu muito (ênfase) com isso, muito” (Lúcia).

A percepção desta profissional sobre a importância da ESF para a articulação da rede e a garantia de um cuidado integral coaduna com a Política Nacional da Atenção Básica (PNAB) (MS, 2012), uma vez que a capilaridade e a proximidade das equipes que compõem a ESF com a comunidade possibilitariam maior contato com o território, a realização de busca ativa aos usuários e o compartilhamento de casos, além de auxílio mútuo entre as equipes. No entanto, esse tipo de trabalho não tem sido realizado, nem com as esparsas equipes de saúde da família existentes no município.

Diversos estudos (Hirdes, 2015; Morais \& Tanaka, 2012; Prata et al., 2017; Quinderé et al., 2013) têm mostrado que o cuidado em saúde mental na Atenção Básica tem sido permeado por certos entraves, uma vez que há uma carência de fluxos adequados entre os variados níveis de atenção. Além da ESF enfrentar dificuldades no sentido de assumir a atenção em saúde mental, não mantendo o seguimento dos casos. Já é identificado um processo inicial de interação entre os diversos componentes da atenção, sendo latente a possibilidade de reorganização das práticas e serviços, muito embora tais mudanças estejam permeadas por conflitos intrínsecos às ações e serviços da Atenção Básica.

Os CAPS, por sua vez, também enfrentam problemas em apoiar essas equipes, não fornecendo ferramentas de capacitação, mobilização e sensibilização para atender essa demanda. Dizendo de outro modo, os profissionais que atendem especificamente a demanda de saúde mental parecem não contribuir significativamente para orientação dos outros serviços que compõem a RAPS, de modo que o restante da rede esteja capacitada para atuar de acordo com o "olhar psicossocial".

Em relação aos dispositivos específicos de saúde mental, como CAPSi, CAPS II, CAPS III, CAPSad III, UAI e Residência Terapêutica, o vínculo e forma de atuação a partir da perspectiva de rede parece ser frágil, fragmentada e com limitações, evidenciando que os serviços atuam de forma desarticulada. Isso pôde ser percebido tanto pelas observações de campo, quanto no momento das entrevistas.

No entanto, o discurso que emerge das falas evidencia que a totalidade dos profissionais entrevistados entendem essa articulação como importante para o serviço, mesmo que 
ela ocorra apenas entre os dispositivos específicos de saúde mental. Em certos momentos, percebemos que alguns dos profissionais de nível médio e superior não sabiam que a Atenção Básica faz parte do que é estabelecido como RAPS pelo MS, atribuindo somente aos equipamentos especializados, acima citados, essa função de componente da rede. Sobre a articulação entre os próprios dispositivos todos os profissionais, relatam que, embora possa melhorar, a coordenação municipal de saúde mental tem investido através da realização de reuniões de equipe para que a perspectiva de rede se fortaleça.

"Acho que a coordenação de saúde mental está trabalhando bastante sobre isso" [sobre a tentativa de tornar a rede mais articulada] (Márcia)

"Aí eu acho que a gente circula melhor" ["circulam melhor" entre eles mesmos, os dispositivos específicos de saúde mental, CAPSi, CAPSII, CAPSIII]. (Bernadete)

Eu acho que a conversa antes era bem mais fechada, hoje a gente tem um diálogo maior. Antes eu percebia que os dispositivos trabalhavam separadamente, né, cada um atendia o seu, era como se não tivesse... se não fosse uma rede. E com a RAPS, isso foi melhorando bastante. A construção da RAPS... acho que tem uns 5 anos mais ou menos, né?! Que aí essa rede foi se formalizando e foi se estruturando mesmo essa Rede de Atenção Psicossocial. (Lúcia)

Abrahão, Azevedo e Gomes (2016) consideram que a prática cotidiana nas unidades de saúde é reconhecida pelas equipes como uma oportunidade para a produção de estratégias que permitem ampliar o cuidado em saúde mental. Os achados das autoras ainda apontam para novos agenciamentos na forma de se cuidar em saúde, além da produção de saberes e conhecimentos a partir do reconhecimento da potência de trabalho no âmbito micropolítico.

No entanto, autores como Mângia e Muramoto (2009) ressaltam o fato de que parece haver uma "crise de operatividade dos serviços" (p. 120), uma vez que há uma tendência de que tais locais não atendam de forma apropriada as solicitações dos usuários, sendo organizados de modo fragmentado a partir das corporações profissionais envolvidas no trabalho. Evidencia-se, assim, a necessidade de elaboração de uma linguagem compartilhada, comum entre todos os atores que integram a rede de serviços no campo da saúde mental.

Essa fragmentação ocorre em vários sentidos a partir do que pôde ser observado em campo. As diversas categorias profissionais parecem se apropriar do discurso de sua própria corporação: os médicos e enfermeiros, adotando o "discurso biológico" das questões de saúde mental, os psicólogos o "discurso psi” e os assistentes sociais, o "discurso social", não tornando factível a premissa "biopsicossocial”.

Além disso, há um outro "dilema" que permeia o cotidiano dos serviços e que também vincula-se à uma discussão corporativa: a realização dos grupos, oficinas e atendimentos individuais. Há um debate sobre o caráter "terapêutico" desses grupos e a possibilidade de realização dos mesmos por todas as categorias de trabalhadores. Em conversa com um dos informantes, o assunto em pauta era a perspectiva transdiciplinar de atuação. Segundo ele, a partir "das políticas do Ministério da Saúde” os grupos e oficinas podem ser realizados por qualquer categoria de trabalhadores, já que a "perspectiva de atuação é uma perspectiva trans". Continua explicando que muitos integrantes da equipe se negavam a realizar os grupos por entenderem que "terapia quem faz é psicólogo" e que isso fugiria de seu ato profissional. A fala de um dos entrevistados confirma tal ideia: "se não conversar com Assistente Social, se não conversar com psicólogo... porque eu não sou terapeuta, eles são, eles fazem terapia, eu não”. (Afonso) 
No entanto, um outro informante defende a ideia de que a partir de uma atuação transdisciplinar possa ocorrer uma união de saberes e práticas, sem que uma anule a outra. Essa visão se ancora nos debates ocorridos no campo da saúde mental de que as perspectivas de atuação nos Centros de Atenção Psicossocial são ou precisam ser "transdisciplinares” (Costa-Rosa, 2013). Nessa linha, Souza e colaboradores (2013) explicam que,

considerando que é uma clínica, em que está presente não só a dimensão subjetiva, mas também a social e a política, é imperativo a interdisciplinaridade, ou até mesmo a transdisciplinaridade dos saberes na construção de uma nova clínica, no campo da saúde mental. A transdisciplinaridade possibilita que os CAPS possam ser gerenciados por qualquer membro da equipe multiprofissional, desde que devidamente qualificado. Porém, a gestão dos serviços especializados em Saúde Mental também tem sido compartilhada com profissionais de outras categorias. A qualificação dos profissionais não "psi”; para atuar nos CAPS, em geral é realizada a partir e sua inserção na área. Percebeu-se que, a qualificação se dá a partir das reuniões técnicas semanais e supervisão clínica-institucional realizada com a equipe quinzenalmente. Em ambas as reuniões, há socialização/transversalidade dos saberes, se constituindo também em um espaço de Educação Permanente. (Souza et al., 2013, p. 74)

Pode-se perceber que a visão do informante coaduna com o exposto na pesquisa realizada por Souza e colaboradores (2013), porém, não há um consenso sobre tal modo de atuação na equipe, visto que os dilemas corporativos persistem.

Retornando aos relatos de Márcia, Bernadete e Lúcia, essas profissionais apontam que a partir da existência de uma política estruturada nacionalmente, há uma preocupação maior com a realização de um trabalho em formato de rede. Nessa direção, indicada pelo Ministério da Saúde, pode-se perceber que ocorre, mesmo que ainda de forma incipiente, o que Mângia e Muramoto (2009) consideram ser uma partilha e demarcação de indicadores e critérios para apoiar a definição de resultados e propostas que contribuam no estabelecimento e avaliação dessas redes. Para tanto, a gestão em saúde mental do município assume um papel fundamental em todo esse processo.

Os dois maiores "nós" encontrados no sentido da atuação em rede a partir da visão dos profissionais dizem respeito ao atendimento ou desatendimento por parte da urgência/emergência e da atenção hospitalar. Cabe ressaltar que o município não conta com leitos de atenção integral nos hospitais gerais. Essa não parece ser uma realidade exclusiva dessa localidade, uma vez que a bibliografia especializada (Dimenstein et al., 2012) aponta para a mesma direção. O relato dos profissionais descreve com clareza a inabilidade para lidar com situações que envolvam o compartilhamento dos casos, tanto com a urgência e emergência quanto com a atenção hospitalar.

Eu já peguei no meu plantão, sempre no meu plantão, dois ou três casos de pacientes, pacientes psiquiátricos, que estavam com enfermidades clínicas, um com tuberculose, outro com pneumonia, que precisavam ser transferidos para um hospital geral, só que o hospital geral não aceita porque tem aquele preconceito (ênfase) de achar que o paciente psiquiátrico não pode ficar doente, ele só tem doença psiquiátrica e ponto final, ele não pode ter aquele quadro, ele não pode ter diarreia, ele não pode ter nada. Esse paciente a gente chegou a ficar com ele 5 horas na ambulância, 6 horas na ambulância, para tentar colocar o paciente no hospital. E ninguém aceitava. (Mariana) 
O termo "preconceito" surge com frequência no campo, tanto por parte do relato profissional quanto pelo que pôde ser constatado pela observação, na fala dos próprios usuários. Embora os mesmos não sejam objeto direto deste artigo, tal percepção é viabilizada pela observação do cotidiano. A discussão empreendida aqui segue as orientações teóricas da discussão sobre "estigma" e "desvio" empreendidas por Goffman (2008) e Becker (2009), uma vez que toda a complexidade das questões que permeiam a dinâmica de funcionamento da rede desemboca no que a vivência profissional aponta como sendo os entraves dessa rede. Ou seja, principalmente pelo fato de as pessoas cuidadas no âmbito da saúde mental viverem sob um constante processo de estigmatização, tanto por parte dos trabalhadores em saúde quanto da sociedade como um todo.

Em relação ao dispositivo específico de álcool e drogas parece ocorrer um duplo processo que envolve, tanto o julgamento moral, uma vez que os usuários do serviço são considerados outsiders, o que interfere em seu cuidado em toda a rede, e o consequente estigma que cresce a partir dessas questões. Afinal, as formas de categorização das pessoas emergem da sociedade transformando certos atributos em desejáveis ou não. Essa designação social inferioriza o indivíduo e o coloca em uma situação de desvantagem ante aos demais (Goffman, 2008). Interessante notar que a noção goffmaniana de estigma permeia este estudo, uma vez que a temática perpassa grande parte das experiências vividas no dispositivo, tanto sob o olhar profissional, quanto de quem usa o serviço.

A categoria elaborada por Goffman surge como algo que, de fato, através de um conjunto de disposições, cria uma relação de desvantagem desses usuários aos demais. No caso descrito acima, apresentando por Mariana, há, pelo que se pode observar, um conjunto de atributos considerados socialmente depreciativos: o estigma da loucura, do uso de álcool e outras drogas e, ainda, a tuberculose, doença fortemente estigmatizada (Porto, 2007; Touso et al., 2014). O estigma sobre a tuberculose pode ser percebido pela fala da mesma profissional, ao afirmar que uma das funcionárias do hospital, no qual tentavam articular uma internação para o paciente, pensou que o CAPSad III desejava tal internação justamente pelo fato de ser uma pessoa com tuberculose:

Aí eu fui explicando pra ela (a enfermeira do hospital), aí que ela foi aceitando o que era um CAPS, porque ela achou que a gente não quisesse o paciente porque estava com tuberculose. (Mariana)

Ressalta-se que a ideia de rede parece quase impossível de se concretizar quando o local de onde se fala é o hospital geral, na visão dos profissionais. O hospital, em uma relação de hierarquia e não poliarquia, como considerado por Mendes (2009), parece ser um local isolado, onde qualquer interlocução tende a tornar-se, assim, intangível. Nos outros componentes, o que se observa é uma falta de diálogo, disputas das mais diversas naturezas, dificuldade no compartilhamento dos casos, atendimentos fragmentados. No entanto, no caso da atenção hospitalar, não há nem essa ideia, uma vez que os leitos não chegam a ser disponibilizados para a realização de tais discussões. Obviamente que esse trabalho se dedica a investigar apenas o CAPSad, conhecendo o discurso apenas unilateralmente. Todavia, nos valendo dos argumentos de Dimenstein e colaboradores (2012), pode-se dizer que há uma grande fragilidade na participação dos hospitais nesse processo, o que gera inúmeros obstáculos. Os autores apontam que há muitos entraves vinculados à reestruturação da RAPS, sendo o estigma ligado às pessoas com transtornos mentais e usuários de álcool e drogas, parte importante desse processo no âmbito hospitalar. 
Além dessas questões, outra fundamental surge do discurso profissional: de que os funcionários da atenção hospitalar desconhecem o que é um CAPS, sua forma de funcionamento e os equipamentos/insumos disponíveis para se prestar um atendimento. Tais questões apontam para o fato de que os próprios profissionais que atuam neste equipamento tendem a considerar a rede de atenção, nos moldes estabelecidos pelo Ministério da Saúde, como algo que para eles só existe em termos formais, mas não na prática.

O pessoal não sabe nem o que é CAPS. Ou outras siglas...UAI. Se você parar para pegar qualquer médico, ele não vai saber te responder, qualquer psicólogo, qualquer que eu digo é que não esteja inserido nesse processo... UAI, UAI é uma interjeição mineira. A gente fica muitas vezes limitado a esse processo. (Afonso)

Porque nem as enfermeiras, nem o médico sabem o que é um CAPS. Acha que o CAPS é um posto de saúde, que tem oxigênio, que tem tudo. Aí eu fui explicar pra ela que o CAPS era uma casa, que tinha enfermeiro, que tinha técnico de enfermagem, que tinha médico, mas era uma casa. (Mariana)

A fala dos profissionais se relaciona com os achados de Dimenstein e colaboradores (2012) e Miranda, Oliveira, Santos (2014), no sentido de que há uma necessidade latente de capacitação dos recursos humanos para lidar com essa demanda e também de conhecer o contexto político da Reforma Psiquiátrica. Tudo isso não apenas para profissionais que trabalham cotidianamente em saúde mental, mas para toda a rede de atenção à saúde. Isso, por sua vez, implica em reformas curriculares nas instituições de ensino superior e educação permanente para os profissionais em serviço. Souza e colaboradores (2013) discutem que tem ocorrido, mesmo que timidamente, uma reformulação nos cursos de graduação que não são da área "psi”, como Serviço Social, Educação Física e Enfermagem, de forma a incluir conteúdos de saúde mental em suas agendas de formação, tendo em vista que a maior parte da qualificação na área de saúde mental tem acontecido a partir da prática profissional, como notamos nos seguintes relatos:

As Assistentes Sociais, Psicólogas me foram passando o que é a Saúde Mental, é bem diferente do que a gente vê na faculdade, que parece ser assustador, é algo bem diferente. (Mariana)

Eu fui muito clara para ela: eu não tenho experiência nenhuma com saúde mental. Nenhuma, porque, a gente quando passa na faculdade você passa só observando, né, a gente sabe da Reforma Psiquiátrica, sabe de tudo, mas você não tem esse embasamento que é trabalhar dentro de um CAPS. (Bárbara)

De acordo com as falas dos entrevistados, percebemos que a necessidade de capacitação profissional surge a partir do cotidiano do serviço, pois o conteúdo oferecido na faculdade é entendido por eles como insuficiente. As reuniões de equipe e organização de grupos de estudo são os principais meios de aperfeiçoamento profissional. Há também um constante relato quanto à falta de investimentos realizados pelo município, em termos de capacitação aos seus profissionais.

Voltando à discussão sobre a atenção hospitalar, é necessário chamar a atenção, mais uma vez, para a aparente despreocupação, ou sentimento de incapacidade frente a não disponibilidade de leitos para atendimento à demanda psiquiátrica e decorrente do uso de álcool e outras drogas. Embora seja notório o apontamento em direção à necessidade de 
criação dos leitos hospitalares, considerando o elevado número de hospitais gerais, sendo dois inclusive municipais, a instituição dos mesmos ainda parece distante da realidade. Nas políticas atuais de saúde mental, o hospital geral surge, ao lado dos CAPS III e unidades de emergência, como instituições fundamentais para a composição da rede em casos de “crises" (Dias, Gonçalves, \& Delgado, 2010).

As situações de crise parecem constituir mais um ponto crítico em relação à atuação em rede e ao cotidiano de trabalho. Estudos no campo da saúde mental e coletiva têm demonstrado entraves nesse sentido. Almeida e colaboradores (2014) discutem que as dificuldades para atender situações de crise em saúde mental estão vinculadas ao baixo conhecimento da equipe acerca desse tipo de atendimento, a partir de uma orientação psicossocial guiada pelos princípios do SUS. Os autores ainda pontuam que o tipo de intervenção realizada em situações de crise continua por reforçar o paradigma biomédico, havendo um escasso investimento por parte da gestão e dos trabalhadores na educação e sistematização do cuidado, além de atitudes baseadas no senso comum. As informações trazidas pelos autores parecem confirmar os achados deste estudo.

O PU é bem difícil trabalhar, sabe, até porque, é coisa do plantão, não tem uma linha de encadeamento, um monte de gente, cada hora um, os médicos também nem todos são psiquiatras, é muito difícil, o PU acho que é o dispositivo mais difícil da rede. (Bernadete)

O município conta com um local na rede de atenção chamado pelos funcionários de "PU Psiquiátrico", mas a nomeação real que aparece no CNES/DATASUS é Pronto Socorro Psiquiátrico. Esse local funciona 24 horas por dia e realiza atendimentos de emergência psiquiátrica. Segundo relatos de campo, o único dispositivo que presta esse tipo de socorro é mesmo o PU, embora a Portaria ${ }^{\circ} 3.088$ de 2011 estabeleça que tanto o Serviço de Atendimento Móvel de Urgência (SAMU) e as Unidades de Pronto Atendimento (UPA) tivessem que abarcar tal demanda. Paralelo a esse fato, as queixas de que o PU Psiquiátrico não corresponde às necessidades da rede são grandes, como notado pela fala da profissional. Sua queixa principal parece girar em torno da questão citada por Almeida e colaboradores (2014), no sentido da ausência de uma formação profissional voltada para o trabalho psicossocial, perpetuando-se formas de atuação puramente biomédicas, onde se apregoa que a urgência psiquiátrica está associada à agressividade, e o surto é entendido como uma descompensação patológica que precisa ser revertida através da reestabilização mental feita por meio da contenção mecânica e/ou química ${ }^{3}$. Enquanto o atendimento psicossocial valoriza a subjetividade, entendendo que a crise precisa ser refletida criticamente, sendo capaz de proporcionar alívio ao sofrimento da pessoa (Almeida et al., 2014).

Um ponto contundente e que corrobora com a ideia de que as práticas realizadas no atendimento de emergência ainda têm sido pautadas em lógicas manicomiais, contrárias ao que é previsto hoje pelas políticas de saúde mental, diz respeito a solicitações de internação psiquiátricas vindas diretamente do PU, sem que a equipe do CAPSad III tome conhecimento do fato afim de realizar algum tipo de intervenção.

3 A contenção mecânica é uma técnica de imobilização frequentemente utilizada nos manicômios e ainda empregue em casos de crises psiquiátricas. Já a contenção química é feita através do uso de medicamentos com alto poder de sedação. 
Tipo... esse cara que eu encontrei lá dentro dos hospitais, hora nenhuma a gente foi acionado, tipo, ah, você já fez tratamento no CAPSad vamos chamar a equipe, né?! (Bernadete)

O que pode endossar tais condutas é o fato de o município ter dois hospitais psiquiátricos funcionantes: um filantrópico e o outro privado, conveniado ao SUS. Segundo informações do campo, a própria existência das instituições psiquiátricas contribui para que familiares dos pacientes solicitem encaminhamento para tais locais e que ocorram internações arbitrárias, sem que a equipe do CAPSad III seja ao menos contactada.

Essa afirmação deriva do fato de que uma clínica municipal para usuários de álcool e outras drogas foi fechada no primeiro semestre de 2016 e há relatos profissionais de que nada foi alterado no cotidiano do serviço. Alguns inclusive afirmaram ter considerado positivo o fechamento, uma vez que as internações não "resolviam o problema". Segundo os profissionais entrevistados, a equipe precisou desenvolver novas estratégias de cuidado para manutenção dos usuários no território, como maior utilização dos leitos internos, por exemplo. Tudo isso proporcionou maior habilidade da equipe frente a situações que antes eram resolvidas com um encaminhamento para a citada clínica, como problemas no território, solicitações familiares e dos próprios pacientes e situações de vulnerabilidade e risco social.

No entanto, as incursões no campo nos mostraram que a RAPS no município estudado ainda é desarticulada e precária, embora haja um conhecimento profissional a respeito da política e de sua importância frente às novas diretrizes de saúde mental. Nossos resultados coadunam com os achados de Dimenstein e colaboradores (2012). As falas dos profissionais do CAPSad III reforçam a falta de clareza e propostas de trabalho que sejam afins, sendo identificado que em relação a alguns componentes não há diálogo algum. Em alguns momentos o discurso apresenta a ideia de rede como algo distante, não factível, o que corrobora para ações pouco comprometidas face à descrença generalizada. Um dos profissionais argumenta que o projeto de atuação em redes não se realiza nas práticas profissionais, ficando restrito ao "papel".

Porque a rede é boa sim, no papel é muito boa, mas... para você conseguir algum atendimento clínico para um paciente é quase impossível, a gente tem que batalhar muito para conseguir que algum, alguma outra parte da rede, ou um hospital geral, alguma coisa assim receba o paciente. (Paulo)

Por fim, há que se ressaltar que a ideia de rede aparece bastante associada ao hospital, esvaziando a importância de outros espaços como a Atenção Básica e os próprios dispositivos de saúde mental. A questão fica frequentemente vinculada à necessidade de atendimento clínico no âmbito hospitalar e às situações de urgência e emergência. Os outros pontos da rede aparecem com pouca frequência durante as entrevistas. Assim, na visão dos profissionais que trabalham para o seu funcionamento, há um certo consenso de que "as redes só existem no papel”, mas não no cotidiano de práticas dos serviços de saúde. 


\section{Conclusões}

A falta de diálogo entre as diversas categorias profissionais, o desconhecimento das políticas de saúde mental e do modus operandi dos CAPS, o preconceito e o estigma ligados à loucura e a quase ausência de capacitação e embasamento técnico para atuação em situações de crise são apontados pelos profissionais como os principais motivos que levam a dificuldade de articulação entre os diversos componentes da RAPS.

No entanto, Franco (2006) argumenta que, mesmo em uma rede fragmentada, a lógica do trabalho no âmbito da micropolítica é sempre em rede, que, por sua vez, tem expressão no meio social diante de diferentes formas de agenciamento. Elas possibilitam novas relações, constroem-se onde os sujeitos estão inseridos, produzindo variadas conexões e fluxos que se estabelecem a partir de todos os processos que interligam os atores e concebem linhas de contatos entre os agentes sociais que produzem a realidade.

Os profissionais entrevistados endossam a necessidade de realização de cursos que abarquem não apenas a temática do uso de álcool e outras drogas em si, mas que englobem todas as potencialidades do agir em rede. Esse trabalho deveria envolver não apenas os profissionais vinculados ao CAPSad, mas todos os membros da Rede de Atenção Psicossocial, possibilitando mudanças no imaginário social em relação à temática, muitas vezes excluída da esfera de debates do âmbito hospitalar, por exemplo.

A pesquisa reafirma os achados de Abrahão, Azevedo e Gomes (2016), no sentido da necessidade de uma agenda pública que valorize os debates relativos à produção de conhecimento, processo de trabalho e educação em saúde mental, "reconhecendo novos atores, novos papéis, novas referências" (2016, p. 67). Mesmo que pelas falas dos trabalhadores em saúde mental surjam inúmeras questões que interpõem as dificuldades do trabalho em rede e a constante desarticulação entre os serviços, há uma percepção em relação à importância dessa forma de trabalho e da não fragmentação para que um cuidado integral e práticas menos excludentes passem a existir. Os esforços dos profissionais vinculados aos serviços demonstram uma preocupação no sentido de transformar o cotidiano de trabalho da unidade, de modo a não fragmentá-lo, reconhecendo a importância da formação das redes para um atendimento integral e humanizado.

\section{Referências}

Abrahão, A. L., Azevedo, F. F. M., \& Gomes, M. P. C. (2017) A produção do conhecimento em saúde mental e o processo de trabalho no centro de atenção psicossocial. Trabalho, Educação e Saúde, Rio de Janeiro, 15(1), 55-71.

Almeida, A. B. et al. (2014). Intervenção nas situações de crise psíquica: dificuldades e sugestões de uma equipe de atenção pré-hospitalar. Revista Brasileira de Enfermagem, Brasília, 67(5), 708-714. Bardin, L. (2010). Análise de conteúdo. Lisboa: Edições 70.

Becker, H. (2009). Outsiders: Estudos de Sociologia do desvio. Rio de Janeiro: Jorge Zahar.

Bonet, O. (2004). Saber e sentir: uma etnografia da aprendizagem da biomedicina. Rio de Janeiro: Editora Fiocruz.

Costa-Rosa, A. (2013). Atenção psicosocial além da Reforma Psiquiátrica: contribuiçães a uma Clínica Crítica dos processos de subjetivação na Saúde Coletiva. São Paulo: Ed. Unesp. 
Dell'Acqua, G. \& Mezzina, R. (1991). Resposta à crise. In J. Delgado (Org.), A loucura na sala de jantar (pp. 53-79). São Paulo: Resenha.

Dias, M. K., Gonçalves, R. W., \& Delgado, P. G. G. (2010). Leitos de atenção integral à saúde mental em hospital geral: configuração atual e novos desafios na política de saúde mental. In E. M. Vasconcelos (Org.), Desafios políticos da reforma psiquiátrica brasileira. (pp. 115-140). São Paulo: Hucitec.

Dimenstein, M. D. et al. (2012). O atendimento da crise nos diversos componentes da rede de atenção psicossocial em Natal/RN. Revista Polis e Psique, 3(2), 95-127.

Elias, P. E. et al. (2006). Atenção Básica em Saúde: comparação entre PSF e UBS por estrato de exclusão social no município de São Paulo. Ciência e Saúde Coletiva, Rio de Janeiro, 11(3), 633-641.

Franco, T. B. (2006). As redes na micropolítica do processo de trabalho em saúde. In R. Pinheiro \& R. A. Mattos (Orgs.), Gestão em Redes: práticas de avaliação, formação e participação na saúde (pp. 459-474). Rio de Janeiro: Cepesc.

Franco, T. B. \& Merhy, E. E. (2004). Programa de Saúde da Família (PSF): contradições de um programa destinado à mudança do modelo tecnoassistencial. In E. E. Merhy (Org.), O trabalho em saúde: olhando e experienciando o SUS no cotidiano (pp. 55-124). São Paulo: Hucitec.

Goffman, E. (2008). Estigma: notas sobre a manipulação da identidade deteriorada (4 ${ }^{\mathrm{a}} \mathrm{ed}$.). Rio de Janeiro: LTC.

Hirdes, A. (2009). A reforma psiquiátrica no Brasil: uma (re) visão. Ciência e Saúde Coletiva, Rio de Janeiro, 14(1), 297-305.

Mângia, E. F. \& Muramoto, M. T. (2009). Modelo de matriz: ferramenta para a construção de boas práticas em saúde mental comunitária. Revista de Terapia Ocupacional da Universidade de São Paulo, São Paulo, 20(2), 118-125.

Mendes, E. V. (2009). As redes de atenção à saúde. Belo Horizonte: Escola de Saúde Pública de Minas Gerais.

Mendes, E. V. (2010). As redes de atenção à saúde. Ciência e Saúde Coletiva, Rio de Janeiro, 15(5), 2297-2305.

Minayo, M. C. S. (1998). O desafio do conhecimento: pesquisa qualitativa em saúde. São Paulo: Hucitec.

Ministério da Saúde. (2011). Portaria n 3.088. Diário Oficial da União, $\mathrm{n}^{\circ}$ 247, de 26-122011, Seção 1, p. 230-232. Recuperado de http://bvsms.saude.gov.br/bvs/saudelegis/gm/2011/ prt3088 $23 \quad 12 \quad 2011$ rep.html

Ministério da Saúde. (2012). Política Nacional de Atenção Básica. Brasilia: Ministério da Saúde. (Série E. Legislação em Saúde). Recuperado de http://189.28.128.100/dab/docs/publicacoes/geral/pnab.pdf

Miranda, L., Oliveira, T. F. K., \& Santos, C. B. T. (2014). Estudo de uma Rede de Atenção Psicossocial: Paradoxos e Efeitos da Precariedade. Psicologia: Ciência e Profissão, Brasília, 34(3), 592-611.

Morais, A. P. P. छ̇ Tanaka, O. X. (2102). Apoio matricial em saúde mental: alcances e limites na atenção básica. Saúde e Sociedade, São Paulo, 21(1), 161-170.

Porto, Â. (2007). Representações sociais da tuberculose: estigma e preconceito. Revista de Saúde Pública, São Paulo, 41(supl.1), 43-49.

Prata, N. I. S. S. et al. (2017). Saúde mental e atenção básica: território, violência e o desafio das abordagens psicossociais. Trabalho Educação e Saúde, Rio de Janeiro, 15(1), 33-53.

Quinderé, P. H. D. et al. (2013). Acessibilidade e resolubilidade da assistência em saúde mental: a experiência do apoio matricial. Ciência e Saúde Coletiva, Rio de Janeiro, 18(7), 2157-2166. 
Souza, A. C., Abrahão, A. L., \& Guljor, A. P. (2016). A conformação da rede de atenção à saúde e sua importância para a garantia de uma atenção integral aos usuários de drogas. In Entre Pedras e fissuras a construção da atenção psicossocial de usuários de drogas no Brasil ( $1^{\mathrm{a}}$ ed., pp. 202215). São Paulo: Hucitec.

Touso, M. M., Popolin, M. P., Crispim, J. A. et al. (2014). Estigma social e as famílias de doentes com tuberculose: um estudo a partir das análises de agrupamento e de correspondência múltipla. Ciênc. Saúde Coletiva, Rio de Janeiro, 19(11), 4577-4586.

Zeferino, M, T., Cartana, M. H. F., Fialho, M. B., Huber, M. Z., \& Bertoncello, K. C. (2016). Percepção dos trabalhadores da saúde sobre o cuidado às crises na Rede de Atenção Psicossocial. Esc. Anna Nery, Rio de Janeiro, 20(3), e20160059. http://dx.doi.org/10.5935/1414$\underline{8145.20160059}$.

\section{ANNABELLE DE FÁTIMA MODESTO VARGAS \\ https://orcid.org/0000-0002-0270-2677}

Cientista social e farmacêutica, mestra em Saúde Coletiva (UFF), doutora em Sociologia Política (UENF), RJ,

e professora do Centro Universitário Redentor (UniRedentor), RJ.

Endereço: BR 356, nº 25, Itaperuna. Rio de Janeiro, CEP 28300-000.

E-mail:annamodesto@hotmail.com

\section{MAURO MACEDO CAMPOS}

https://orcid.org/0000-0001-9472-5165

Doutor em Ciência Política pela Universidade Federal de Minas Gerais (UFMG), pós-doutorado em Ciência Política pela UNICAMP e professor e pesquisador associado da Universidade Estadual do Norte Fluminense (UENF), RJ.Endereço: Av. Lourival de Melo Mota -Tabuleiro do Martins Maceió-AL - CEP: 57072-970.

E-mail: mauromcampos@yahoo.com.br

\begin{tabular}{|l|l|}
\hline \multirow{2}{*}{ Histórico } & $\begin{array}{l}\text { Submissão: 01/11/2017 } \\
\text { Revisão: 07/02/2019 } \\
\text { Aceite: 09/12/2019 }\end{array}$ \\
\hline & $\begin{array}{l}\text { Concepção: A.F.M.V.; M.M.C. } \\
\text { Coleta de dados: A.F.M.V }\end{array}$ \\
$\begin{array}{l}\text { Análise de dados: A.F.M.V.; M.M.C. } \\
\text { dos autores }\end{array}$ & $\begin{array}{l}\text { Elaboração do manuscrito: A.F.M.V.; M.M.C. } \\
\text { Crítica de conteúdo intelectual importante: A.F.M.V.; M.M.C. }\end{array}$ \\
\hline Aprovação final do manuscrito: A.F.M.V.; M.M.C. \\
\hline $\begin{array}{l}\text { Financiamento } \\
\text { Consentimento de } \\
\text { uso de imagem }\end{array}$ & $\begin{array}{l}\text { Foi obtido o consentimento escrito dos participantes } \\
\text { e/ou do detentor dos direitos autorais sobre a imagem. }\end{array}$ \\
\hline
\end{tabular}

